\title{
Reduced-Intensity Transplant Conditioning Procedure
}

National Cancer Institute

\section{Source}

National Cancer Institute. Reduced-Intensity Transplant Conditioning Procedure. NCI

Thesaurus. Code C116471.

A method of preparation for stem cell transplant that uses less than standard doses of chemotherapy and radiation prior to the transfer of stem cells, with the goal of providing protection against graft vs. host disease, while simultaneously minimizing the toxic effects of the conditioning treatment. 